\title{
Dopamine-GABAergic mechanisms of rearing and locomotion in infant and weanling mice
}

\author{
EZIO TIRELLI and CHRISTINE JODOGNE \\ Université de Liège au Sart Tilman, Liège, Belgium
}

\begin{abstract}
This ontogenetic study examined the modulatory effects of the GABA-A agonist muscimol on supported rearing and locomotion induced by the indirect dopamine agonist D-amphetamine. Infant 14-day-old, weanling 20-day-old, and adult 53-day-old outbred mice were tested. In the adult mice, muscimol at $1.3 \mathrm{mg} / \mathrm{kg}$ attenuated $2 \mathrm{mg} / \mathrm{kg}$ D-amphetamine-induced locomotion but not rearing, whereas $1.9 \mathrm{mg} / \mathrm{kg}$ muscimol blocked both behaviors. While $0.025 \mathrm{mg} / \mathrm{kg}$ muscimol reduced $2 \mathrm{mg} / \mathrm{kg} \mathrm{D}$-amphetamine-induced rearing without altering locomotion in infants, it affected neither rearing nor locomotion in weanlings. At this age, $0.075 \mathrm{mg} / \mathrm{kg}$ muscimol blocked both behaviors well. In the infant mice, however, this dose of muscimol engendered gnawing and self-biting, a typical effect of dopamine-GABAergic pharmacological activation. A smaller dose of $1.25 \mathrm{mg} / \mathrm{kg}$ $\mathrm{D}$-amphetamine was necessary to avoid this effect and to obtain a direct attenuation of locomotion and rearing. Given that we have previously obtained an attenuation of D-amphetamine-induced locomotion and wall climbing (which is mostly displayed by preweanling murines) with muscimol in 8- and 11-day-old neonatal mice pups (Tirelli, 1989a), it is concluded that maturation of dopamine-GABAergic behavioral functions follows a near-monotonic continuity starting a few days after birth.
\end{abstract}

Among the well-known motor patterns of behavioral hyperactivity induced by pharmacological dopamine activation in laboratory rodents, there are a number of vertically exhibited behaviors. For instance, the direct dopamine agonist apomorphine produces strong climbing on the walls of a wire mesh cage in mice and some populations of rats (Davis, Jenner, \& Mardsen, 1986; Protais, Costentin, \& Schwartz, 1976). These effects cannot be induced by indirect dopamine agonists, such as D-amphetamine or methylphenidate. Nevertheless, at low to mild dosages, these agonists and apomorphine accelerate ambulation and, in certain conditions, enhance the number of rears (Bryan \& Ellison, 1975; Decsi \& Nagy, 1988; Russell, Giordano, \& Sanberg, 1987).

Rearing and climbing are not only under dopaminergic control but also depend strongly on GABA activity, as suggested by a number of studies in which these behaviors, facilitated by a dopamine agonist, are dosedependently attenuated by GABA and various GABA agonists (Dunn, Kruse, Geyer, Novick, \& Fielding, 1980; Georgiev, Getova, \& Petkov, 1984). Rearing has also been found to be directly inhibited by enhanced central

The authors thank H. Depoortere (Synthélabo, Bagneux, France) for the generous gift of muscimol hydrobromide, and $\mathrm{H}$. Lejeune (University of Liège, Belgium) and P. Terry (National Institute on Drug Abuse, Baltimore, MD) for their valuable comments and corrections. Christine Jodogne is a research assistant at the Fonds National de la Recherche Scientifique (FNRS, Belgium). Correspondence should be addressed to Ezio Tirelli, who is now at the Laboratory of Psychobiology, National Institute on Drug Abuse, Addiction Research Center, P.O. Box 5180, Building C, Baltimore, MD 21224
GABAergic activity (following injection of inhibitors of the GABA catabolic enzyme GABA-transaminase) at doses that do not affect locomotion (Benton \& Rick, 1976; Nobrega, Snow, Dixon, \& Coscina, 1988). In fact, GABAergic agonists reduce the enhancing effects of dopamine agonists on general behavioral activity, which probably involves rearing rather than just locomotion, as measured by electronic activometers (Cott \& Engel, 1977; Menon \& Clark, 1979; Scheel-Kruger, Christensen, \& Arnt, 1978). Such effects may also be obtained by infusing GABA, muscimol, or other GABA agonists into caudate, striato-pallidal, and thalamic structures (Decsi \& Nagy, 1988; Ossowska, Wedzony, \& Wolfarth, 1984; ScheelKruger, 1986). Moreover, rearing and locomotion can be directly suppressed by local GABA activation or strongly facilitated by the GABA antagonists picrotoxin and bicuculline, whose effects resemble those induced by peripherally injected dopamine agonists (Decsi \& Nagy, 1988; Scheel-Kruger, 1986; Vrijmoed-de Vries, Tönissen, \& Cools, 1987). On the basis of such studies and others combining intracerebral infusions into two areas, ScheelKruger has speculatively suggested that systemically injected GABA agonists may temper the dopamine-dependent behaviors by inhibitory action in the above-mentioned nuclei (Scheel-Kruger, 1986).

From studies of the early ontogeny of the neuropharmacology of vertically exhibited behaviors, it appears that the output dopamine systems subserving rearing in rats and mice are probably operative in infants and weanlings. Thus, rearing may be markedly increased by cocaine, $\mathrm{D}$-amphetamine, and piribedil in 14-, 15-, 17-, and 21-day-old rats, and by $\mathrm{D}$-amphetamine in 16-day-old mice 
(Alleva, Castellano, \& Oliverio, 1979; Bauer, 1980, 1984; Reinstein, MacClearn, \& Isaacson, 1978; Spear \& Brick, 1979). In 14-day-old rats, apomorphine and piribedil can also enhance wall climbing, defined as scraping or alternate forepaw movements against the wall of the apparatus with the body in a near-vertical plane (Reinstein et al., 1978; Shalaby \& Spear, 1980). In a previous study (Tirelli, 1989a), it was found that this behavior induced by D-amphetamine can be attenuated by subthreshold doses of muscimol in neonatal mice aged 5 to 11 days, suggesting a very early maturation of at least some elements of a dopamine-GABA articulation subserving behavioral activities.

In the present study, our purpose was to examine whether this pharmacological association produces the same effect on rearing in weanling 20-day-old and infant 14-dayold mice, the age at which an adult-like pattern of supported rearing clearly emerges (Tirelli, 1986-1987; Van Abeelen, 1968; Van Abeelen \& Schoones, 1977). The detection of such an effect in maturing mice would testify to an early functioning of the dopamine-GABA coordination underlying rearing. In preliminary experiments, we have ascertained that $D$-amphetamine did produce the expected behavioral increases among our developing mice, as has been reported in previous studies for locomotor activity (Forster \& Nagy, 1984; Thornburg \& Moore, 1973).

\section{EXPERIMENT 1}

\section{Method}

Animals and breeding. Mice of an outbred albino CarworthFarms-derived stock (OF-1 strain, IFFA-CREDO, Oncins, France) were bred in the laboratory colony and kept in plastic cages $(17 \times 22 \times 15 \mathrm{~cm})$, with free access to food and water. Room temperature was maintained at $23^{\circ} \mathrm{C} \pm 1^{\circ} \mathrm{C}$, with a 12-h light cycle beginning at $0800 \mathrm{~h}$. Groups of 4 females were housed with a single sire, and vaginal smears were taken every day at $1000-1100 \mathrm{~h}$ and $1600-1700 \mathrm{~h}$. The day on which sperm was found was designated Day 1 of gestation. The day of birth was considered Day 0 of postnatal life. At birth, the dams were housed separately with their litters. All litters were reduced to 6 male pups per litter within $48 \mathrm{~h}$ of birth. The 53-day-old mice had been weaned on Day 27; the animals remained in the same cage from which the dam was removed.

A total of 216 mice-53, 20, or 14 days old-were the subjects. Each age group included 72 animals taken from 12 litters.

Apparatus. Rearing and locomotion were monitored in clear acrylic ambulometers adapted to each age group, with floors made from a $1.5-\mathrm{mm}$-thick sheet of duralumin perforated with $5-\mathrm{mm}$ diameter equidistant holes. Adult mice aged 53 days were tested in cages measuring $26.5 \times 9.5 \times 12.5 \mathrm{~cm} ; 14$ - and 20 -day-old mice were tested in cages measuring $22 \times 8 \times 9.5 \mathrm{~cm}$. Two photocells were located $4 \mathrm{~cm}$ from each end of the experimental cage. As in Forster and Nagy (1984), one locomotor activity count was registered each time a mouse crossed the full distance berween the photocells, breaking alternate beams. This distance was $18.5 \mathrm{~cm}$ for the 53-day-old mice and $14 \mathrm{~cm}$ for the developing mice. Photocells were placed on the two longer sides of the ambulometer, at a height of $2 \mathrm{~cm}$ for the adult mice and $1.4 \mathrm{~cm}$ for the developing mice. The inner walls of each chamber were covered with duralumin sheets up to a height adapted to each age group: $7.5,5$, or $4 \mathrm{~cm}$ above the floor.
As described by Bauer $(1980,1984)$, the recording circuit for rearing was programmed to register a rearing count when the forelimbs of the mouse touched the metallic sheets of the walls, thereby completing the electrical circuit between these and the floor. A minimal duration of $0.1 \mathrm{sec}$ was required to record one rearing count. Another rearing count could be recorded after a short interruption (at least $0.1 \mathrm{sec}$ ) of the contact between the wall and the floor. Data were recorded and printed out by a Rockwell AIM-65 computer. During all sessions, the mice were tested in sound-attenuated, artificially ventilated and illuminated boxes $(80 \times 90 \times 75 \mathrm{~cm})$, with small one-way windows allowing visual observation.

Procedure. All behavioral testing was carried out between 1000 and $1700 \mathrm{~h}$. The mice were first weighed and tail-marked with a felt tip pen. One mouse from each litter was randomly assigned to one of the six drug conditions according to a split-litter design and following a 3 (muscimol) $\times 2$ (amphetamine) drug-treatment schedule. Muscimol hydrobromide (Synthélabo, Bagneux, France) and D-amphetamine sulfate (Fédéra, Brussels, Belgium) were dissolved in $0.9 \mathrm{CaCl}$ saline solution, so that the volume to be injected was always $0.01 \mathrm{ml} / \mathrm{g}$ body weight. The doses of both muscimol and D-amphetamine were adapted to each age group, given that previous experiments had shown large age-related differences in pharmacological susceptibility, especially for the GABA-A agonist. Nonmaximally efficient doses of $D$-amphetamine were selected in order to maximize the potential inhibitory action of muscimol on its behavioral effects. By testing for catalepsy and ataxia (suspension of forepaws onto a horizontal wire), only nonsedative doses of muscimol were selected.

The 53-day-old mice were subcutaneously injected with either $0.9 \%$ saline solution, 1.3 , or $1.9 \mathrm{mg} / \mathrm{kg}$ muscimol $15 \mathrm{~min}$ prior to receiving an intraperitoneal injection of saline solution or $2 \mathrm{mg} / \mathrm{kg}$ D-amphetamine. The developing 20 - and 14-day-old mice received either saline solution, 0.025 , or $0.075 \mathrm{mg} / \mathrm{kg}$ muscimol and, $15 \mathrm{~min}$ later, saline solution or $2 \mathrm{mg} / \mathrm{kg}$ D-amphetamine. Fifteen minutes after the second injection, the mice were put into the ambulometer singly and recording began immediately. Supported rearing and locomotion (crossings) were scored per 20-min intervals over an 80-min test session.

Because muscimol has been reported to induce gnawing in adult and developing mice when injected with D-amphetamine or other dopamine agonists (Scheel-Kruger et al., 1978; Tirelli, 1987), we watched the animals through the one-way window of the box to see if this occurred. A simple time-sampling procedure was applied. After 25,50 , and $75 \mathrm{~min}$ of recording, each mouse was checked for $10 \mathrm{sec}$ for the potential presence of gnawing or other oral behaviors. The mice were not habituated to the apparatus before testing and were used only once.

Design and data analysis. A mixed analysis of variance (ANOVA) was applied at each age group on the number of rears or crossings. Litters were considered as a random factor (12 blocks). Muscimol (three levels) and D-amphetamine (two levels) were considered as fixed variables crossed factorially within litters. Interval of time (four levels) was a within-subjects variable (Kirk, 1982). Dunn's tests (1961), derived from the appropriate error mean squares, were used for pairwise comparisons involving muscimol dose versus the logical control (saline + amphetamine-treated mice or saline-treated controls). Significance levels were established at $\alpha=0.05$. Unless otherwise specified, it is these analyses that are cited in the text. Pooled SEMs, based upon the appropriate error mean squares involved in the comparisons between means, are included in the figures.

\section{Results}

Mice aged 53 days. Figure 1 depicts rearing activity (top panels) and locomotion (bottom panels) as a function of treatments and intervals in adult 53-day-old mice. 
53 DAYS OF AGE

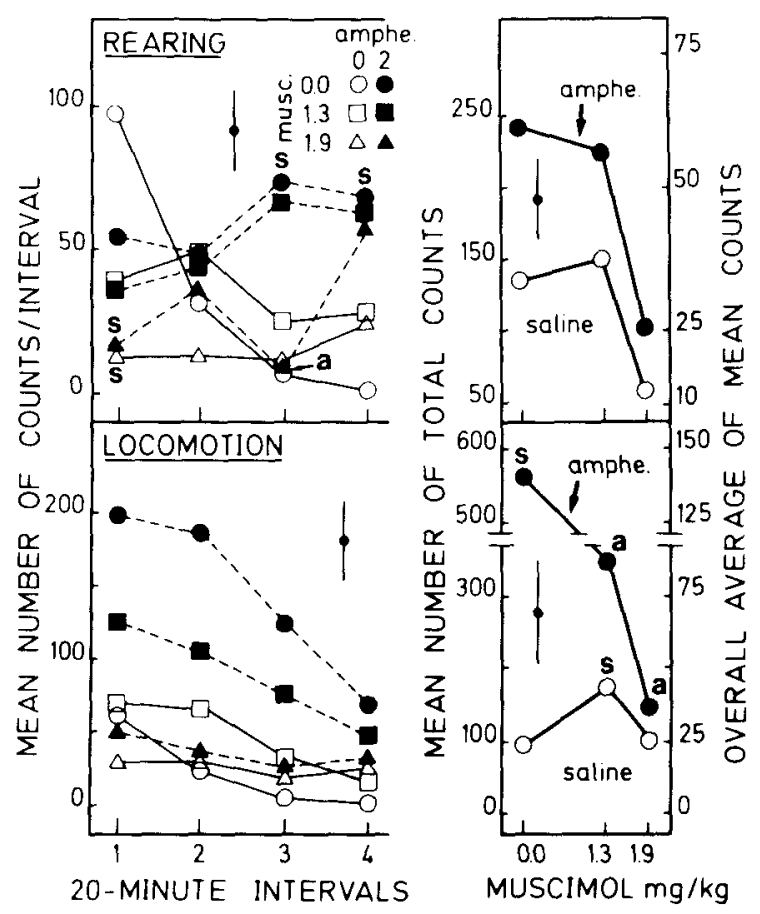

Figure 1. Effects of muscimol at 1.3 or $1.9 \mathrm{mg} / \mathrm{kg}$ s.c. on the enhancing action of $2 \mathrm{mg} / \mathrm{kg}$ D-amphetamine i.p. on automatically recorded supported rearing and locomotion in adult 53-day-old mice. The GABA-A agonist was injected $30 \mathrm{~min}$ before recording; the indirect dopamine agonist $15 \mathrm{~min}$ before recording. The two left graphs present the results as a function of successive 20-min intervals (potential second-order muscimol $x$ amphetamine $x$ interval interactions). The two right panels show the behavioral activity summed over the whole duration of the monitoring $(80 \mathrm{~min})$ and the overall average of mean counts per interval (potential first-order muscimol $\times$ amphetamine interactions). The vertical bars represent pooled SEMs $(\times 2)$ derived from the appropriate error mean squares. $s, p<.05$, as compared with the saline + saline group; $a, p<.05$, as compared with the saline + amphetamine group (Dunn's tests).

As can be seen in the top left panel, the saline-treated controls showed a sharp decline in rearing over the intervals, reflecting habituation to the test chamber, whereas the amphetamine-treated mice displayed a clear-cut increase in rearing in the third and fourth intervals (saline + amphetamine-treated group). Muscimol at $1.9 \mathrm{mg} / \mathrm{kg}$ tempered the high levels of rearing induced by amphetamine during the first and third intervals, but not at the second and fourth ones. The lower dose of muscimol $(1.3 \mathrm{mg} / \mathrm{kg})$ had no effect on amphetamine's action. The mice treated with saline $+1.9 \mathrm{mg} / \mathrm{kg}$ muscimol exhibited very low levels of rearing during the first interval, whereas the saline-treated controls showed intense rearing activity here. This profile was supported by a significant secondorder interaction between muscimol, amphetamine, and interval $[F(6,66)=2.59, p<.025]$. The lower dose of muscimol also reduced rearing at the first interval and slightly enhanced it during the following intervals, com- pared with the rearing of the saline-treated controls. However, this effect was not significant in terms of the second-order interaction. Nevertheless, a less conservative ANOVA on only the mean number of rears per interval between the saline-treated and saline $+1.3 \mathrm{mg} / \mathrm{kg}$ muscimol-treated groups yielded a significant interaction between muscimol and interval $[F(3,33)=2.91, p<.05]$. Appropriate Dunn's tests confirmed these effects of muscimol for the first (reduction) and fourth (augmentation) intervals.

Without considering interval in the analysis (mean number of rears calculated across intervals or mean number of total counts; top right panel of Figure 1), the effects of muscimol and amphetamine in the adults' rearing data appeared to be mainly additive. Indeed, the interaction was far from statistical significance $(F<1)$.

An ANOVA on mean number of locomotor counts in the 53-day-old mice revealed a robust interaction between muscimol and amphetamine $[F(2,22)=10.67, p<.001]$ and no second-order interaction between muscimol, amphetamine, and interval $(F<1)$. As can be seen in the bottom left panel of Figure 1, this was because overall amphetamine-induced hyperlocomotion was attenuated by $1.9 \mathrm{mg} / \mathrm{kg}$ muscimol. In addition, the levels for the mice receiving $1.3 \mathrm{mg} / \mathrm{kg}$ muscimol + amphetamine were significantly different both from the mice injected with saline + amphetamine and the saline-treated controls. The interaction between muscimol and amphetamine is better represented in the bottom right graph of Figure 1.

Muscimol at $1.3 \mathrm{mg} / \mathrm{kg}$ (with saline) slightly enhanced locomotion, most notably during the second and third intervals. An ANOVA did not confirm such differences (no significant second-order interaction). This effect was supported only using a less conservative ANOVA on means of the saline-treated controls and the $1.3 \mathrm{mg} / \mathrm{kg}$ muscimol + saline-treated mice; this yielded a significant interaction between muscimol and interval $[F(3,33)=2.92, p<$ $.050]$ and a main effect of muscimol $[F(1,11)=4.86$, $p<.050]$.

Mice aged 20 days. An ANOVA on mean number of rearing counts of 20-day-old mice (Figure 2 ) revealed a significant second-order interaction between muscimol, amphetamine, and interval $[F(6,66)=4.78, p<.0004]$ and a first-order interaction between muscimol and amphetamine $[F(2,22)=4.24, p<.030]$. This analysis supports the trends indicated in the top panels of Figure 2. As can be seen (top left panel), saline + amphetaminetreated mice made significantly more rears than did the saline-treated mice, particularly at the third and fourth intervals. This excitation was completely reversed by the higher dose of muscimol $(0.075 \mathrm{mg} / \mathrm{kg})$, but not by the lower dose of $0.025 \mathrm{mg} / \mathrm{kg}$. Moreover, it appeared that the mice treated with $0.075 \mathrm{mg} / \mathrm{kg}$ muscimol + amphetamine exhibited rearing scores lower than those exhibited by the saline controls, particularly at the first and second intervals. Dunn's tests confirmed the increase of rearing activity induced by $0.025 \mathrm{mg} / \mathrm{kg}$ muscimol, especially during the second, third, and fourth intervals. 


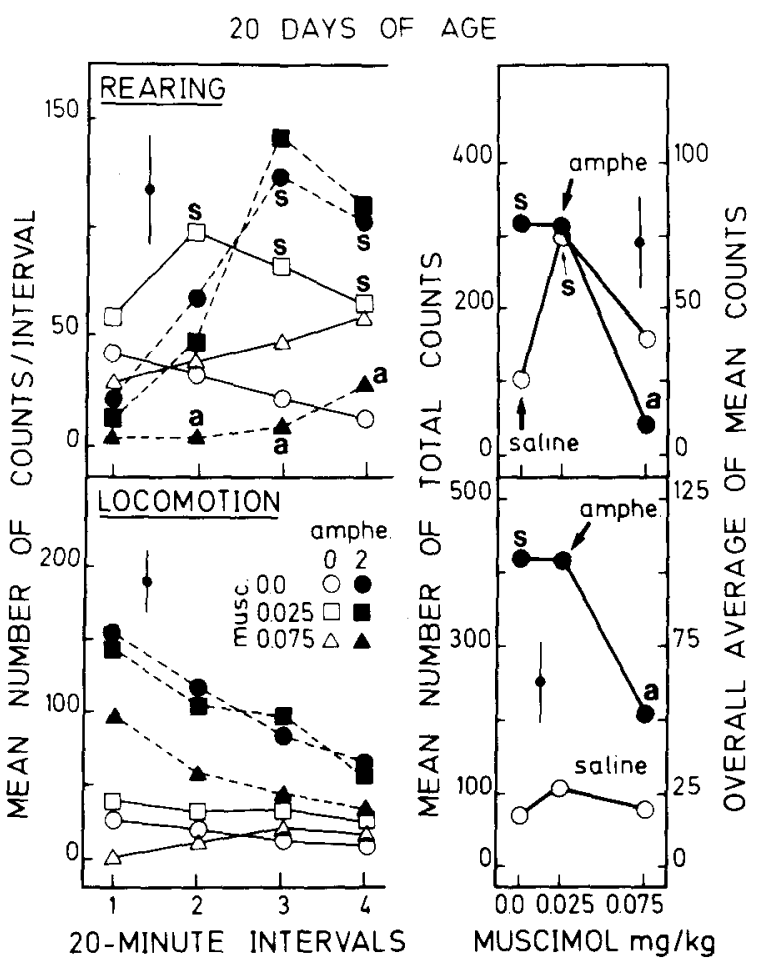

Figure 2. Effects of muscimol at 0.025 or $0.075 \mathrm{mg} / \mathrm{kg}$ s.c. on the enhancing action of $2 \mathrm{mg} / \mathrm{kg}$ D-amphetamine i.p. on automatically recorded supported rearing and locomotion in weanling 20-day-old mice. See also the caption of Figure $1 . s, p<.05$, as compared with the saline + saline group; a, $p<.05$, as compared with the saline + amphetamine group (Dunn's tests).

The enhancement of locomotion by amphetamine in the 20-day-old mice was also attenuated, but not reversed, by $0.075 \mathrm{mg} / \mathrm{kg}$ muscimol at each of the intervals, as represented in Figure 2 (bottom left panel). The smaller dose of muscimol $(0.025 \mathrm{mg} / \mathrm{kg})$ did not affect hyperlocomotion in the saline + amphetamine-treated group. This pattern was corroborated by a significant first-order interaction between muscimol and amphetamine $[F(2,22)=$ $7.58, p<.004$ ], along with the absence of a significant second-order interaction between the three factors under study. Subsequent Dunn's tests indicated that the GABA-A agonist attenuated the action of amphetamine only after injection of $0.075 \mathrm{mg} / \mathrm{kg}$ muscimol (for the first-order interaction and the total counts analysis, see Figure 2, bottom right panel). There was no clear excitatory effect of muscimol on locomotion, unlike for rearing.

Mice aged 14 days. An ANOVA on mean number of rearing counts for the 14-day-old mice yielded significant interactions between muscimol, amphetamine, and interval $[F(6,66)=4.80, p<.0005]$ and between muscimol and amphetamine $[F(2,22)=5.09, p<.015]$. As shown in Figure 3 (top left panel), amphetamine alone (with saline) enhanced rearing at the third and fourth intervals. The saline-treated controls showed their highest levels of rearing during the second interval and their lowest levels at the end of the fourth (habituation). The dose of $0.025 \mathrm{mg} / \mathrm{kg}$ muscimol, inactive by itself, reversed the excitatory action of amphetamine during the second, third, and fourth intervals. At $0.075 \mathrm{mg} / \mathrm{kg}$, muscimol almost completely suppressed rearing, not only when injected with amphetamine but also with saline. This suggests that this suppression was due to an excessive inhibitory effect of $0.075 \mathrm{mg} / \mathrm{kg}$ muscimol per se rather than to a specific inhibition of the amphetamine effect. As can be seen in the top left panel of Figure 3, this effect was particularly strong during the second interval (Dunn's test not shown in the figure).

Looking at the overall average of mean counts (top right panel of Figure 3), it appears that the levels of rearing activity in the $0.075 \mathrm{mg} / \mathrm{kg}$ muscimol + saline and $0.075 \mathrm{mg} / \mathrm{kg}$ muscimol + amphetamine groups were 15fold smaller than were those seen for the saline-treated control group. These differences probably reflect the nonspecificity of the higher dose of muscimol on amphetamineinduced rears, as mentioned before.

An ANOVA on mean number of crossings per interval for the 14-day-old mice indicated a reliable interaction between muscimol and amphetamine $[F(2,22)=6.14$, $p<.007$ ], but not between these factors and interval. That analysis supported a uniform enhancement of loco-

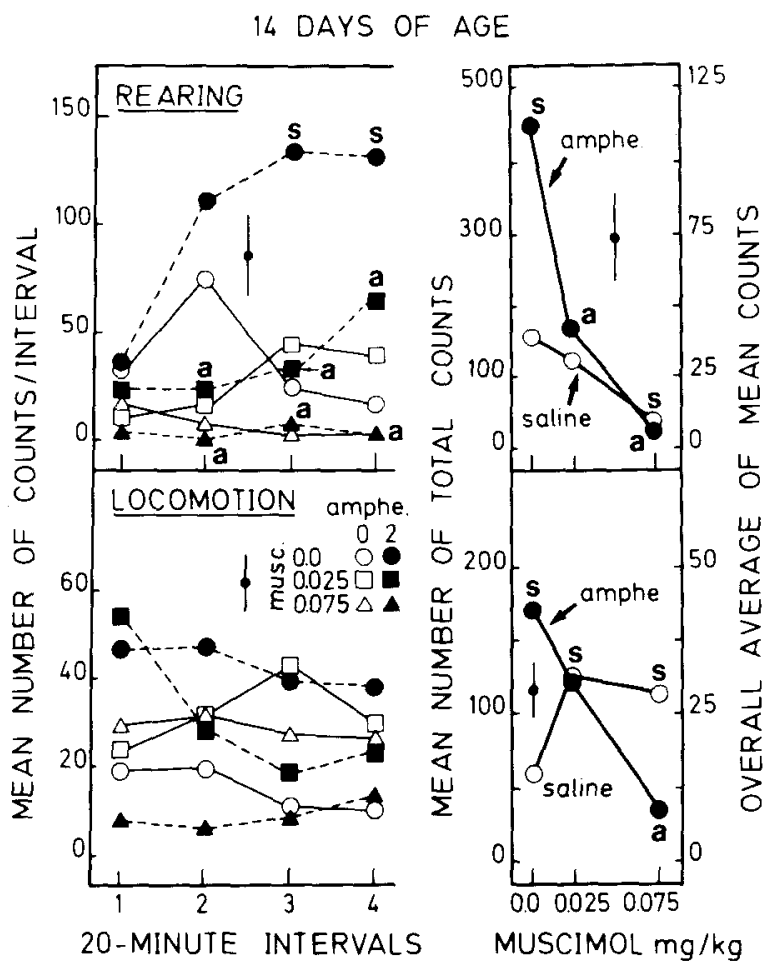

Figure 3. Effects of muscimol at 0.025 or $0.075 \mathrm{mg} / \mathrm{kg}$ s.c. on the enhancing action of $2 \mathrm{mg} / \mathrm{kg}$ D-amphetamine i.p. on automatically recorded supported rearing and locomotion in infant 14-day-old mice. See also the caption of Figure 1. s, $p<.05$, as compared with the saline + saline group; $a, p<.05$, as compared with the saline + amphetamine group (Dunn's tests). 
motor activity by amphetamine over the four intervals. This effect was counteracted by muscimol at $0.075 \mathrm{mg} / \mathrm{kg}$, with comparable efficiency at each interval (see bottom left graph of Figure 3). At $0.025 \mathrm{mg} / \mathrm{kg}$, muscimol attenuated the increase in locomotion by amphetamine, but not significantly so, even after a less conservative analysis of the saline + amphetamine and $0.025 \mathrm{mg} / \mathrm{kg}$ muscimol + amphetamine groups.

Furthermore, the GABA-A agonist alone (with saline) also produced a significant stimulation of locomotion at both dosages, as is evident by comparison of the saline + muscimol-treated groups with the saline-treated control group. This effect contributed to the first-order interaction between muscimol and amphetamine represented in the bottom right panel of Figure 3.

Direct observation findings. During ambulometer recordings, nearly all of the 14-day-old infant mice from the $0.075 \mathrm{mg} / \mathrm{kg}$ muscimol + amphetamine group $(n=12)$ showed gnawing and self-biting, whereas the mice in the other experimental and age groups did not gnaw or selfbite (see Table 1). Gnawing was directed towards the perforations of the floor. Self-biting resembled an exacerbated and continuous facial, thoracic, and/or forelimb grooming. However, in the infant mice treated with $0.025 \mathrm{mg} / \mathrm{kg}$ muscimol + D-amphetamine, rearing returned to control levels and locomotion was slightly attenuated, without oral behaviors being engendered (Figure 3 ).

\section{Discussion}

In Experiment 1, it appears that muscimol robustly attenuated the effects of D-amphetamine on supported rearing and/or locomotion in all age groups under study: 14, 20 , and 53 days old. In the adult mice, while the dose of $1.9 \mathrm{mg} / \mathrm{kg}$ muscimol blocked the effects of the dopamine indirect agonist not only on rearing but also on locomotion, the lower dose of $1.3 \mathrm{mg} / \mathrm{kg}$ muscimol exerted its attenuative action only on locomotion. It should be noted that the higher dose of the GABA-A agonist alone significantly suppressed rearing without affecting loco-

Table 1

Number of 14-Day-Old Mice (from a total of 12 per group) Exhibiting Gnawing or Self-Biting Following Saline, 0.025, or $0.075 \mathrm{mg} / \mathrm{kg}$ Muscimol Prior to $2 \mathrm{mg} / \mathrm{kg}$ D-Amphetamine

\begin{tabular}{cccc}
\hline $\begin{array}{c}\text { Dose } \\
\text { of Muscimol } \\
(\mathrm{mg} / \mathrm{kg})\end{array}$ & $\begin{array}{c}\text { Time Sampling } \\
\text { After Onset } \\
\text { of Monitoring (min) }\end{array}$ & Gnawing & Self-Biting \\
\hline Saline & 25 & 0 & 0 \\
& 50 & 0 & 0 \\
0.025 & 75 & 0 & 0 \\
& 25 & 0 & 0 \\
0.075 & 50 & 0 & 0 \\
& 75 & 0 & 0 \\
& 25 & $5 *$ & 6 \\
& 50 & 5 & 7 \\
\hline
\end{tabular}

Note-All data was collected (during time samplings of $10 \mathrm{sec}$ ) by direct observation through a one-way window 25,50 , and $75 \mathrm{~min}$ after the beginning of rearing and locomotion monitoring in ambulometers. * These 5 mice were also checked within the other samplings. motion. These effects confirm those published by Benton and Rick (1976) and Nobrega et al. (1988), who have described the same dissociation after the injection of an indirect GABA agonist in rats.

In the weanlings, muscimol robustly attenuated the action of D-amphetamine on rearing and on locomotion at $0.075 \mathrm{mg} / \mathrm{kg}$, but not at $0.025 \mathrm{mg} / \mathrm{kg}$. By contrast, this latter dose of muscimol had convincing inhibitory effects on amphetamine-induced rearing, and it tended to block hyperlocomotion in the infant 14-day-old mice. The effects of $0.075 \mathrm{mg} / \mathrm{kg}$ muscimol in the amphetamine-treated mice at this age were twofold: reduced levels of rearing and locomotion accompanied by episodes of gnawing and self-biting. In fact, it seems likely that the diminished levels of rearing and locomotion resulted directly from staying in one place while exhibiting oral behaviors rather than from an adult-like selective action of muscimol on D-amphetamine. Such effects are in line with data we have previously obtained in immature 8-day-old mice and with self-biting recorded in 14-day-old subjects with methylphenidate as dopamine agonist (10 or $20 \mathrm{mg} / \mathrm{kg}$ ) (Tirelli, 1987). Self-biting was also elicited in 20-day-old and, less effectively, in adult mice (Tirelli, 1990). In fact, by selecting appropriate dosages, these two aspects of the pharmacological dopamine-GABA interaction (the GABAergic attenuative action on dopamine-dependent general behavioral activity and the GABAergic facilitative action on dopamine-dependent oral behaviors) can be obtained separately (Scheel-Kruger et al., 1978).

The mechanisms by which muscimol, and other agents enhancing central GABA activity, facilitate oral behaviors seem to involve the lifting of GABAergic inhibition within the substantia nigra (facilitated by a dopamine activation in the striatum), which results in the disinhibition of the GABA pathways directed onto various output stations (Baumeister \& Frye, 1984; Scheel-Kruger, 1986). Interestingly, oral responses to muscimol infusions within this cerebral area have also been described in infant rats aged 15-16 days (Moshé \& Albala, 1984). The absence of oral behaviors among the 20-day-old mice, along with the age differences in muscimol's effects on D-amphetamineinduced supported rearing and locomotion, again reveal the lowering of sensitivity to the GABA-A agonist with increasing age (see Method section; Tirelli, 1987, 1989a).

Muscimol alone (saline + muscimol groups) produced increases in rearing and/or locomotion at each age. Notably, rearing levels of the 20 -day-old mice were two to three times higher in the group treated with saline + $0.025 \mathrm{mg} / \mathrm{kg}$ muscimol than the rearing levels of the mice not receiving the drug. This dose of muscimol also produced an excitation, especially on locomotion, in the 14-day-old animals; $1.3 \mathrm{mg} / \mathrm{kg}$ muscimol slightly, but significantly, increased both rearing and locomotion in the adult mice. Such effects are in accordance with those typically reported after relatively low dosages of GABA agonists in adult, as well as in neonatal, rodents (Gardner \& Piper, 1982; Scheel-Kruger et al., 1978; Spear, Penson, \& Linville, 1986; Tirelli, 1989b). The mechanisms of 
these enhancing effects have not yet received a convincing explanation. We have systematically examined elsewhere the ontogeny of the motoric responsiveness to muscimol in infant and weanling mice (Tirelli, Jodogne, \& Perikel, 1990).

It seems likely that the dose of D-amphetamine used in Experiment 1 was excessive and probably the cause of the oral behaviors elicited in our infant 14-day-old mice, thus impeding the expression of the modulatory action of muscimol on locomotion (although the lower dose of $0.025 \mathrm{mg} / \mathrm{kg}$ muscimol did moderate rearing without inducing oral behaviors). Experiment 2 was designed to clarify this point by trying to completely separate the attenuative action of muscimol on locomotion from the facilitative one on oral behaviors. Supported rearing was also recorded. A smaller but effective dose of D-amphetamine $(1.25 \mathrm{mg} / \mathrm{kg})$ was combined with the highest dose of muscimol $(0.075 \mathrm{mg} / \mathrm{kg})$ used in Experiment 1 .

\section{EXPERIMENT 2}

\section{Method}

Seventy-two mice aged 14 days were taken from 12 litters and randomly assigned to one of three treatment schedules, with the constraint that two pups per litter be placed into a given treatment condition. Treatments were as follows: saline $(0.9 \%)+$ saline, saline $+1.25 \mathrm{mg} / \mathrm{kg}$ D-amphetamine, and $0.075 \mathrm{mg} / \mathrm{kg}$ muscimol + $1.25 \mathrm{mg} / \mathrm{kg} \mathrm{D}$-amphetamine. Where Levene's test for homogeneity of variance was statistically significant (Glaser, 1983), the raw data were square-root transformed to yield homogenous variances, thereby more nearly meeting the assumptions for parametric analysis of variance. In all other aspects, the procedure and apparatus were identical to those of Experiment 1.

\section{Results and Discussion}

An ANOVA on the rearing data revealed a significant interaction between treatment and interval $[F(6,30)=$ $4.65, p<.002]$ and a main effect of treatment $[F(2,10)=$ $5.47, p<.025]$. Subsequent Dunn's tests indicated that $0.075 \mathrm{mg} / \mathrm{kg}$ muscimol attenuated the enhancing action of D-amphetamine after 40,60 , and $80 \mathrm{~min}$ of monitoring. Furthermore, as presented in the top left panel of Figure 4, at the second interval, the animals treated with muscimol + amphetamine exhibited levels of supported rearing markedly lower than did the saline-treated controls.

An ANOVA on the locomotion data revealed a significant main effect of treatment $[F(2,10)=10.80, p<.004]$ and a significant interaction between treatment and interval $[F(6,30)=3.43, p<.010]$. Pairwise comparisons showed that, although levels of locomotion did not differ reliably between the saline-treated controls and the saline + amphetamine-treated mice at the first and second intervals, the saline + amphetamine-treated animals exhibited significant hyperlocomotion during the second part of testing (bottom left panel of Figure 4). In particular, muscimol significantly tempered amphetamine-induced hyperlocomotion at each of the four intervals, suppressing the third interval peak.

An ANOVA on the mean number of counts summed over the $80 \mathrm{~min}$ of monitoring (see the right panels of
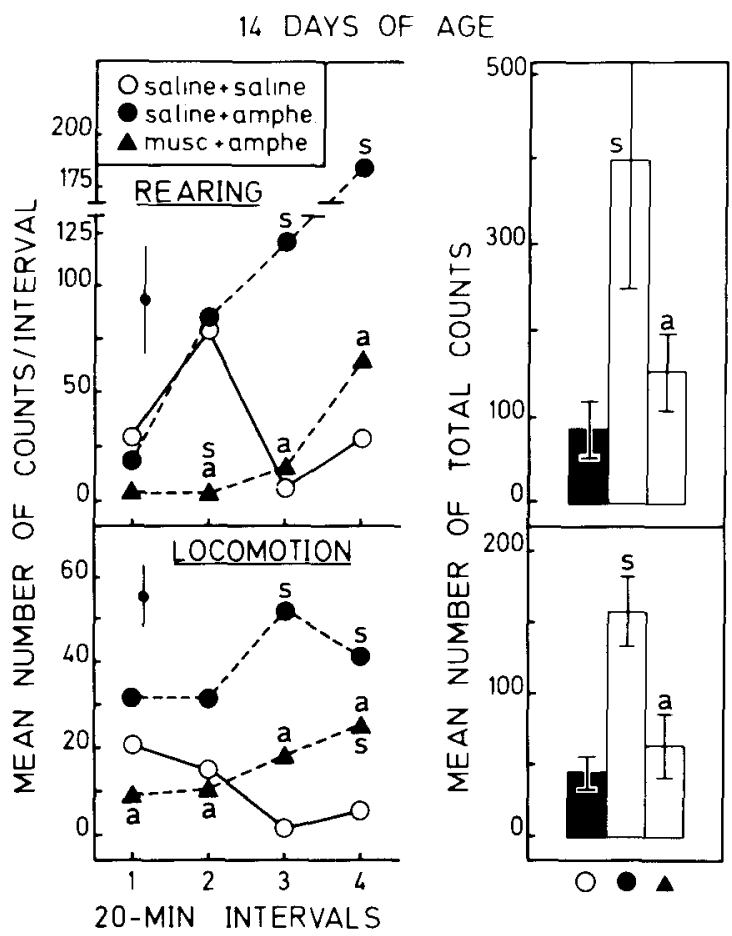

Figure 4. Effects of muscimol at $0.075 \mathrm{mg} / \mathrm{kg}$ s.c. on the enhancing action of D-amphetamine at $1.25 \mathrm{mg} / \mathrm{kg}$ i.p. on rearing and locomotion in 14-day-old mice as a function of 20-min intervals. Right graphs present the behavioral activity summed over the total duration of recording ( $80 \mathrm{~min}$ ). The vertical brackets on bars indicate SEMs for the mean number of total counts. See also the caption of Figure 1. s, $p<.05$, as compared with the saline + saline group; a, $p<.05$, as compared with the saline + amphetamine group (Dunn's tests).

Figure 4), followed by Dunn's tests, confirmed the effects of muscimol on amphetamine-induced locomotion and supported rearing $[F(2,10)=13.16, p<.002$, and $F(2,10)=5.48, p<.025$, respectively].

Visual observation through the one-way windows indicated that oral behaviors were not exhibited by the muscimol + amphetamine-injected infant animals. This strongly suggests that, unlike in Experiment $1(2 \mathrm{mg} / \mathrm{kg}$ D-amphetamine), attenuation of dopamine-dependent hyperlocomotion was not due to gnawing and/or self-biting while resting, that is, to a reciprocal relationship between the oral behaviors versus locomotion and rearing. Hence, the oral behaviors observed in the mice treated with $0.075 \mathrm{mg} / \mathrm{kg}$ muscimol and $2 \mathrm{mg} / \mathrm{kg}$ amphetamine mainly depend on an excessive dopaminergic activation induced by the indirect dopamine agonist.

\section{GENERAL DISCUSSION}

In these experiments, it was observed that high levels of supported rearing and locomotion induced by amphetamine can be robustly moderated by the GABA-A agonist muscimol at 1.3 and $/$ or $1.9 \mathrm{mg} / \mathrm{kg}$ in adult 53-day-old mice and at 0.025 and $/$ or $0.075 \mathrm{mg} / \mathrm{kg}$ in weanling 20-day- 
old mice and infant 14-day-old mice (Experiment 1). A smaller dose of the indirect dopamine agonist $(1.25 \mathrm{mg} / \mathrm{kg}$ rather than $2 \mathrm{mg} / \mathrm{kg}$ ) was necessary specifically to obtain these effects in the infant mice without causing gnawing and self-biting (Experiment 2). It should be noted that the action of muscimol on rearing in the developing animals was not clearly induced without a somewhat concomitant attenuation of locomotion (even if the effect of muscimol on infant mouse locomotion was not statistically reliable). This tends to suggest that the action of the GABA-A agonist on supported rearing was not specific to this behavior but was probably related to drug-induced changes in general behavioral activity of immature mice. In the adult mice, although a nonsedative dose of $1.3 \mathrm{mg} / \mathrm{kg}$ muscimol tempered amphetamine-induced hyperlocomotion, it did not affect rearing levels. On the other hand, $1.9 \mathrm{mg} / \mathrm{kg}$ muscimol injected after saline produced a selective decrease in rearing, with locomotion practically unchanged. Such qualitative differences between adult and developing mice may reflect specific differences in neurobehavioral organization at each age, which confer different frequencies of rearing and locomotion from one developmental stage to another.

Shah, Hanlin, Eargle, and Yates (1980) have published results on the ontogeny of dopamine-GABA systems and behavioral functions that are in substantial accordance with ours. Young rats aged $12-13$ or $20-22$ days treated with $10 \mathrm{mg} / \mathrm{kg} \mathrm{D,L-baclophen} \mathrm{(a} \mathrm{GABA-B} \mathrm{agonist)} \mathrm{in} \mathrm{combi-}$ nation with $20 \mathrm{mg} / \mathrm{kg}$ methylphenidate (an indirect dopamine agonist) showed much less general behavioral activity (electronic activometer) than did solely methylphenidatetreated ones. However, baclophen at this dose produced catalepsy (as indicated by the results of Shah et al., as well as by our own laboratory experience with GABA agonists) among 12-13-day-old rats. Hence, the results for this age are more likely due to a strong general behavioral depression rather than to a selective interaction with dopamine mechanisms.

The present results complete those one of us has previously reported using an observational technique with neonatal mice aged 5, 8, and 11 days (Tirelli, 1989a). Pups displayed reduced levels of D-amphetamine-induced wall climbing, head raising, and locomotion following injections of nonsedative doses of muscimol. Wall climbing was the behavior most sensitive to the attenuative effects of the GABA-A agonist, as was the case for rearing in our 14-day-old mice. These data, along with the present findings, provide strong evidence for a maturational continuity, from the neonatal period to adulthood, of the articulated dopamine-GABAergic systems engaged in behavioral regulation.

This pattern contrasts with the complex ontogeny of the cholinergic involvement in wall climbing, rearing, and locomotion. Thus, anticholinergic agents (scopolamine, atropine) can potentiate wall climbing induced by stressful footshocks and rearing (supported and unsupported) in weanling and adult rats but can induce the opposite effect in infants, suggesting an articulated ontogeny of a neu- ral substrate common to these behaviors (Bauer, 1982, 1984; Blozovski \& Bachevalier, 1975; Linville \& Spear, 1988). Interestingly, Decsi and Nagy (1988) have recently shown that the attenuative effects of GABA and muscimol infusions (rat caudate nucleus) on rearing induced by systemically injected apomorphine are functionally independent from those obtained after cholinergic activation with carbachol infusions, GABA and cholinergic antagonists being effective only when associated with their respective agonist. The fact that the ontogenetic pattern of GABAergic effects on rearing and wall climbing sharply differs from that of the cholinergic effects indirectly supports these results.

A comparable dissimilarity between GABAergic and cholinergic modulation of dopamine-dependent behaviors also appears in locomotor data. Indeed, it has been well known since the early work of Campbell and his coworkers (see the review by Mabry \& Campbell, 1977) that agents that postsynaptically either mimic or block the action of acetylcholine do not influence (by potentiation or antagonism) amphetamine-induced locomotion before the middle or end of the third postnatal week. In contrast, the GABA-A agonist muscimol antagonizes this effect from Day 8 of age in mice (Tirelli, 1989a; also see present results). Furthermore, in neonatal 5-day-old mice, muscimol can also restore normal levels of "lying still" behavior (the most prominent behavior in the newborn's ethogram) that was suppressed by $10 \mathrm{mg} / \mathrm{kg}$ methylphenidate (Tirelli, 1986-1987).

Recent evidence strongly suggests that GABAergic pathways, which are located beyond dopaminergic striatal regions in murid mesencephalon and midbrain, transmit and mediate dopaminergic functions towards peripheral output stations (Scheel-Kruger, 1986). This implies that the functioning of GABA systems is indispensable to the expression of dopamine-dependent behaviors. In this context, it is easy to conceive that behavioral functions related to both groups of systems emerge near-concomitantly in ontogeny. On the other hand, cholinergic neurons seem to be functionally articulated below the level of dopaminergic ones, allowing for independent activity of the latter during maturation (Decsi \& Nagy, 1988; Mabry \& Campbell, 1977; Scheel-Kruger, 1986; Wiggins, MacCandless, \& Enna, 1985).

\section{REFERENCES}

Alleva, E., Castellano, C., \& Oliverio, A. (1979). Ontogeny of behavioral development, arousal and stereotypies in two strains of mice. Experimental Aging Research, 5, 335-350.

BAUER, R. H. (1980). The effects of L-, D- and parahydroxyamphetamine on locomotion activity and wall-climbing in rats of different ages. Pharmacology, Biochemistry \& Behavior, 13, 155-165.

BAUER, R. H. (1982). Age-dependent of scopolamine on avoidance, locomotor activity, and rearing. Behavioural Brain Research, 5, 261-279.

BAUER, R. H. (1984). Differential effects of amphetamine and scopolamine on the ontogeny of rearing. Pharmacology, Biochemistry \& Behavior, 21, 321-323.

Baumeister, A. A., \& Frye, G. D. (1984). Self-injurious behavior in 
rats produced by intranigral microinjection of GABA agonists. Phar macology, Biochemistry \& Behavior, 21, 89-95.

BENTON, D., \& RICK, J. T. (1976). The effect of increased brain GABA produced by amino-oxyacetic acid on arousal in rats. Psychopharmacology, 49, 85-89.

Blozovski, D., \& BaCheVAlier, J. (1975). Effect of atropine on behavioral arousal in the developing rat. Developmental Psychobiology, 8, 97-102.

Bryan, K. S., \& Ellison, G. (1975). Cholinergic modulation of an opposed effect of D-amphetamine and methylphenidate on the rearing response. Psychopharmacologia, 43, 169-173.

CotT, J., \& Engel, J. (1977). Suppression by GABAergic drugs of the locomotor stimulation induced by morphine, amphetamine and apomorphine: Evidence for pre- and postsynaptic inhibition of catecholamine systems. Journal of Neural Transmission, 40, 253-268.

Davis, A. S., Jenner, P., \& Mardsen, C. D. (1986). A comparison of motor behaviours in groups of rats distinguished by their climbing response to apomorphine. British Journal of Pharmacology, 87, 129-137.

DECSI, L., \& NAGY, J. (1988). Independent GABAergic and cholinergic modulation of apomorphine-induced stereotyped rearing in the rat. Neuropharmacology, 27, 281-285.

DunN, O. J. (1961). Multiple comparisons among means. Journal of the American Statistical Association, 56, 52-64.

DunN, R. W., Kruse, H., Geyer, H. M., Novick, W. J., \& FIELDING, S. (1980). The effects of GABA-agonists and -antagonists on apomorphine-induced climbing behavior. Brain Research Bulletin, 5(Suppl. 2), 433-437.

Forster, M. J., \& NAGY, Z. M. (1983). Potentiation of locomotor activity by $\mathrm{d}$-amphetamine in infant Swiss-Webster mice. Physiological Psychology, 11, 278-282.

GARDNer, C. R., \& PiPER, D. C. (1982). Effects of agents which enhance GABA-mediated neurotransmission on licking conflict in rats and exploration in mice. European Journal of Pharmacology, 83, 25-33.

Georgiev, V., Getova, D., \& Petkov, V. (1984). GABAergic influence on the effects of elymoclavine on exploratory behaviour of rats in open field. Methods \& Findings in Experimental \& Clinical Pharmacology, 6, 423-427.

GLASER, R. E. (1983). Levene's robust test of homogeneity of variances. In S. Kotz, N. L. Johnson, \& C. B. Read (Eds.), Encyclopedia of statistical sciences (Vol. 4, pp. 608-610). New York: Wiley.

KIRK, R. E. (1982). Experimental design: Procedure for the behavioral sciences. Belmont, CA: Brooks/Cole.

Linville, D. G., \& SPEAR, L. P. (1988). Cholinergic influences on wall climbing and its ontogenetic decline. Psychopharmacology, 95, 200-207.

Mabry, B. D., \& CampBell, B. A. (1977). Developmental psychopharmacology. In L. L. Iversen, S. D. Iversen, \& S. H. Snyder (Eds.), Handbook of psychopharmacology (Vol. 7, pp. 393-444). New York: Plenum.

Menon, M. K., \& ClaRK, W. G. (1979). GABA-ergic drugs block the locomotor stimulant effects of 1,3-dimethyl-5-aminoadamantane (D-145). Neuropharmacology, 18, 223-225.

Moshé, S. L., \& Albala, B. J. (1984). Nigral muscimol infusions facilitate the development of seizures in immature rats. Developmental Brain Research, 13, 305-308.

Nobrega, J. N., Snow, J., Dixon, L. M., \& Coscina, D. V. (1988). Graded increases in brain GABA: Differential effects on feeding and other behaviours in rats. Behavioural Brain Research, 31, 135-187.

OssowsKa, K., WEDZONY, K., \& WOLFARTH, S. (1984). The role of GABA mechanisms of the globus pallidus in mediating catalepsy, stereotypy and locomotor activity. Pharmacology, Biochemistry \& Behavior, 21, 825-831.

Protais, P., Costentin, J., \& SChWARTZ, J. (1976). Climbing behavior induced by apomorphine in mice: A simple test for the study of dopamine receptors in striatum. Psychopharmacology, 50, 1-6.
Reinstein, D. K., MacClearn, D., \& Isaacson, R. L. (1978). The development of responsiveness to dopaminergic agonists. Brain Research, 150, 216-224.

Russell, K. H., Giordano, M., \& Sanberg, P. R. (1987). Amphetamine-induced on- and off-wall rearing in adult laboratory rats. Pharmacology, Biochemistry \& Behavior, 26, 7-10.

SCHEEL-KRUGER, J. (1986). Dopamine-GABA interactions: Evidence that GABA transmits and mediates dopaminergic functions in the basal ganglia and the limbic system. Acta Neurologica Scandinavica, 73(Suppl. 107), 1-54.

Scheel-Kruger, J., Christensen, A. V., \& ARnt, J. (1978). Muscimol differentially facilitates stereotypy but antagonizes motility induced by dopaminergic drugs: A complex GABA-dopamine interaction. Life Sciences, 22, 75-84.

Shah, N. S., Hanlin, J., Eargle, D., \& Yates, J. (1980). Effects of gamma-amino butytic acid (GABA) and baclophen on the methylphenidate-induced behavior in rats during ontogenesis. Brain Research Bulletin, 5(Suppl. 2), 525-529.

Shalaby, I. A., \& Spear, L. P. (1980). Psychopharmacological effects of low and high doses of apomorphine during ontogeny. European Journal of Pharmacology, 67, 451-459.

SPEAR, L. P., \& Brick, J. (1979). Cocaine-induced behavior in the developing rat. Behavioral \& Neural Biology, 26, 401-415.

Spear, L. P., Penson, J., \& Linville, D. G. (1986). GABA and behavioral inhibition in the neonatal rat pup. Psychopharmacology, 92 , 106-111.

Thornburg, J. E., \& Moore, K. E. (1973). Postnatal development of benztropine-induced locomotor stimulation: Evidence for a cholinergic mechanism of action. Research Communications in Chemical Pathology \& Pharmacology, 6, 313-320.

TIRELLI, E. (1986-87). Larticulation dopamine-GABA: Aspects ontogénétiques de son expression comportementale chez la souris. [The dopamine-GABA articulation: Ontogenetic aspects of its behavioral expression in the mouse]. Unpublished doctoral dissertation, University of Liège, Liège (Belgium).

TIRELLI, E. (1987). Ontogeny of GABA-ergic and dopaminergic mediation of gnawing behavior in the mouse. Psychopharmacology, 92, 89-95.

TIRELLI, E. (1989a), Functional maturation of the GABAergic inhibition on dopamine-mediated behaviours during the neonatal period in the mouse. Behavioural Brain Research, 33, 83-95.

TIRELLI, E. (1989b). The GABA-A agonist muscimol facilitates muscular twitches and locomotor movements in the mouse. Pharmacology, Biochemistry \& Behavior, 33, 497-500.

TIRELLI, E. (1990). Age-dependent sex differences in the behavioral expression of the dopamine-GABA articulation: Comparison of adult with weanling mice. Manuscript in preparation.

TIRELL, E., Jodogne, C., \& PERIKEL, J.-J. (1990). Adult-like biphasic neurobehavioral changes induced by a GABA-A agonist in infant and weanling mice. Manuscript submitted for publication.

VAN ABEELEN, J. H. F. (1968). Behavioral ontogeny of looptail mice. Animal Behaviour, 16, 1-4.

VAN Abeelen, J. H. F., \& Schoones, A. H. (1977). Ontogeny of behavior in two inbred lines of selected mice. Developmental Psychobiology, 10, 17-23.

VRIJMOED-DE VRIEs, M. C., Tönissen, H., \& CoOLs, A. R. (1987). The relationship between hindlimb disturbances, forelimb disturbances and catalepsy after increasing doses of muscimol injected into the striatal-pallidal complex. Psychopharmacology, 92, 73-77.

Wiggins, R. C., MacCANdless, D., \& EnNa, S. J. (Eds.) (1985). Developmental neurochemistry. Austin, TX: University of Texas Press.

(Manuscript received December 14, 1989; revision accepted for publication September 24, 1990.) 